\title{
Fetal MRI in the Identification of a Fetal Ventral Wall Defect Spectrum
}

\author{
Peter W. Coleman, MD ${ }^{1}$ Megan B. Marine, MD ${ }^{2}$ Jennifer N. Weida, MD ${ }^{3}$ Brian W. Gray, MD \\ Deborah F. Billmire, $\mathrm{MD}^{4}$ Brandon P. Brown, MD, MA ${ }^{2}$
}

\footnotetext{
${ }^{1}$ Department of Radiology and Imaging Sciences, Indiana University School of Medicine, Indianapolis, Indiana

2 Department of Radiology and Imaging Sciences, Indiana University

School of Medicine, Indianapolis, Indiana

${ }^{3}$ Department of Obstetrics and Gynecology, Indiana University

School of Medicine, Indianapolis, Indiana

${ }^{4}$ Department of Surgery, Indiana University School of Medicine,

Indianapolis, Indiana
}

Am J Perinatol Rep 2018;8:e264-e276.
Address for correspondence Brandon Brown, MD, MA, Department of Radiology and Imaging Sciences, Indiana University School of Medicine, 705 Riley Hospital Drive, Room 1053, Indianapolis, IN 46202 (e-mail: brpbrown@iupui.edu).

\begin{abstract}
Keywords

- OEIS

- cloacal exstrophy

- limb-body wall complex

- body stalk anomaly

- pentalogy of Cantrell

- fetal MRI

Objective To ascertain if useful criteria for prenatal diagnosis of fetal ventral body wall defects (VBWDs) exists by reviewing published literature on diagnosis of VBWD as compared with our own diagnostic experience.

Study Design A comprehensive literature review of diagnostic criteria of fetal VBWD including pentalogy of Cantrell (POC), omphalocele, exstrophy, imperforate anus, spina bifida (OEIS), cloacal exstrophy, limb-body wall complex (LBWC), and body stalk anomaly was performed followed by a retrospective review of all fetal magnetic resonance imaging (MRI) examinations from our medical center over a 2-year period. Results Classically, OEIS is omphalocele, bladder exstrophy, imperforate anus, and spina bifida. POC is defects of the supraumbilical abdomen, sternum, diaphragm, pericardium, and heart. LBWC is two of the following: exencephaly or enencephaly with facial clefts, thoracoschisis or abdominoschisis, and limb defects. Twenty-four cases of VBWD on MRI over a 24-month period were identified with seven cases involving defects of additional organ systems. Six of these seven cases demonstrated findings from two or more of the traditional diagnoses POC, OEIS, and LBWC making diagnosis and counseling difficult.

Conclusion There is a lack of consensus on useful diagnostic criteria within the published literature which is reflected in our own diagnostic experience and poses a challenge for accurate prenatal counseling.
\end{abstract}

Fetal ventral body wall defects (VBWDs) comprise a range of congenital malformations of widely varying severity and prognosis. Some can be isolated and relatively straightforward, involving high rates of survival to delivery and successful postnatal surgical repair, such as uncomplicated gastroschisis. ${ }^{1}$ Others involve abnormalities of multiple organ systems and have been described as uniformly fatal, such as limb-body wall complex (LBWC). ${ }^{2}$ Several entities

received

May 3, 2018

accepted after revision

September 17, 2018
DOI https://doi.org/

10.1055/s-0038-1675353. ISSN 2157-6998. previously thought to be unique, such as cloacal exstrophy and omphalocele, exstrophy, imperforate anus, spina bifida (OEIS) complex, are now regarded by many as one and the same. ${ }^{3}$ Conversely, some conditions initially thought to be represented by a single phenotype, such as pentalogy of Cantrell (POC), have recently been described as having partial presentations. ${ }^{4,5}$ Distinct from uncomplicated omphalocele, which has its own unique developmental
Copyright $\odot 2018$ by Thieme Medical Publishers, Inc., 333 Seventh Avenue, New York, NY 10001, USA. Tel: +1(212) 584-4662.
License terms

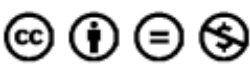


pathophysiology and association with abnormal karyotypes, other types of VBWD involve some degree of failure of fusion of the lateral and craniocaudal body folds around the umbilical ring during the 5th and 6th weeks of gestation. While a few sources have suggested there may be a genetic basis for certain types of these VBWD, ${ }^{6}$ the majority indicates that these patients nearly always have a normal karyotype. $^{7-9}$

With improvements in prenatal diagnostic methods, VBWDs are now often detected earlier in utero. Consequently, an interdisciplinary team of maternal-fetal medicine (MFM) physicians, neonatologists, pediatric surgeons, pediatric radiologists, and various other subspecialists can be involved in diagnosis, prognostication, and family counseling. Aberrations of the fetal ventral body wall can be detected in the late first or early second trimester, during screening ultrasound (US). At our center, this typically leads to a referral to MFM and subsequent expert US. Further evaluation with fetal magnetic resonance imaging (MRI) is performed for cases in which the diagnosis is in question, lung and/or herniated organ volume measurement are desired, or suspected neurological anomalies require further characterization.

Diagnosis is often not in question when the VBWD is an isolated defect such as gastroschisis or bowel-only omphalocele. However, when the defect is more complex, involving the thorax, pelvis, neural tube, limbs, or genitourinary system, there can be greater diagnostic difficulty. While there are certainly some published case reports and case series describing patients whose imaging findings fit neatly within established diagnostic criteria, many others do not. For these other cases, the findings may straddle multiple diagnoses or may be best described as "hybrid." Indeed, many cases initially published as representative of a certain VBWD were later critiqued in subsequent reports as having been misclassified. Similarly, multiple retrospective studies that reanalyzed prenatal imaging found high discrepancy rates between the clinical imaging report and the diagnosis reached during the study. ${ }^{7,10-13}$ This apparent lack of consensus raises questions regarding the benefit of too rigid and adherence to the traditional diagnostic categories within the range of VBWD. Further, a review of recent cases encountered within our own prenatal diagnostic clinic confirms the disparate reports in the literature, and the theme that many patients present with overlapping features of different VBWD. The practice of prenatal diagnosis depends on the ability to counsel families appropriately regarding expected outcomes, and we suggest that the current paradigm is too dependent on rigid diagnostic categories that do not account for those hybrid cases frequently reported in the literature and seen in our own cohort.

\section{Materials and Methods}

The Institutional Review Board of our academic health care system approved this retrospective imaging study with waiver of written participant consent.

\section{Literature Review}

An extensive review of the literature was performed. First, recent articles pertaining to the radiologic diagnosis of VBWDs were identified through a PubMed search of "diagnosis" AND each key phrase: "pentalogy of Cantrell" (155 results), “OEIS” (60 results), “cloacal exstrophy” (214 results), "limb-body wall complex" (69 results), and "body stalk anomaly" (BSA) (56 results). These were reviewed and a subset of publications which focused on prenatal imaging diagnosis was identified and summarized. Further critical review determined the seminal papers for each diagnosis, from which a narrative of the diagnostic history of each entity was produced. Next, case reports and case series gathered in the initial PubMed search of each entity were systematically reviewed to collate diagnostic criteria, common findings, and reported findings (- Table $\mathbf{1}$ and - Fig. $\mathbf{1}$ ).

\section{Case Series}

The institutional radiology database was queried for MRI of pregnant females over a 24-month period from January 2016 to January 2018. A total of 364 studies were identified, 24 (6.5\%) of which demonstrated findings of VBWD. Cases of isolated omphalocele and gastroschisis were excluded, leaving a total of 7 out of 24 (29\%) studies.

Review of these imaging examinations revealed that MRI was performed for a variety of clinical indications including concern for fetal pathology, suspected morbidly adherent placenta, or concern for maternal intra-abdominal inflammatory process.

Maternal clinical and demographic information were obtained from retrospective chart review, including maternal age, gestational age (GA), parity, race, health conditions, and medications used during pregnancy. Clinical information about the fetus was obtained from chart review and included: maternal parity and pertinent medical history, findings on prenatal US and prenatal MRI, GA at the time of these studies, results of genetic testing, GA at delivery, delivery history, placenta pathologic examination results, intrapartum and neonatal outcomes, surgical interventions and intraoperative findings, mortality, and autopsy results.

US imaging studies were performed via transabdominal technique via GE Voluson 730 (GE Electric Medical System, Milwaukee, WI) with an abdominal convex probe of $3.5 \mathrm{MHz}$.

MRI studies were obtained from a Siemens 3.0 tesla scanner (MAGNETOM Skyra; Siemens, Erlangen, Germany). Exact pulse sequences differed depending on the indication for MRI, but included half-Fourier acquisition single-shot fast spin-echo, balanced steady-state free precession, T1 spoiled gradient echo, echo planar imaging, and diffusion-weighted imaging. All scans utilized included three planes of imaging.

\section{Results}

Seven cases of prenatal MRI were identified for review. The MRI examinations were performed between 25 and 37 weeks' GA. For each case, GA at MRI, prenatal imaging diagnosis, GA at birth, delivery type, Apgar score (when applicable), length of neonatal hospital stay, type of neonatal 
Table 1 Reported fetal findings by diagnosis

\begin{tabular}{|c|c|}
\hline \multicolumn{2}{|c|}{ OEIS complex/cloacal exstrophy } \\
\hline \multirow[t]{5}{*}{ Diagnostic criteria } & Four key criteria in the acronym \\
\hline & Omphalocele \\
\hline & Exstrophy of the bladder \\
\hline & Imperforate anus \\
\hline & Spina bifida \\
\hline \multirow{30}{*}{$\begin{array}{l}\text { Proposed common } \\
\text { findings }\end{array}$} & Kidney malformations (up to $60 \%$ of cases $^{49}$ ) \\
\hline & Hydroureter $^{49,50}$ \\
\hline & Hydronephrosis ${ }^{49-51}$ \\
\hline & Congenital megaureter $^{16,52}$ \\
\hline & Pelvic kidney ${ }^{16,53,54}$ \\
\hline & Duplex kidney ${ }^{16,54}$ \\
\hline & Renal dysplasia ${ }^{51,55}$ \\
\hline & Cystic dysplasia $^{16,49,50}$ \\
\hline & Renal agenesis ${ }^{49,50,52,55-57}$ \\
\hline & Limb anomalies \\
\hline & Clubfoot with vertical talus ${ }^{50}$ \\
\hline & Limb length discrepancy ${ }^{53}$ \\
\hline & 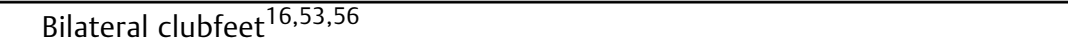 \\
\hline & Neural tube defects ${ }^{57,58}$ (70\% of cases $^{49}$ ) \\
\hline & Spina bifida, myelocystocele ${ }^{49}$ \\
\hline & Terminal myelocystocele ${ }^{16,53,54}$ \\
\hline & Lumbosacral spina bifida 51,56 \\
\hline & Hindbrain herniation, lipomyelomeningocele ${ }^{16}$ \\
\hline & Omphalocele $16,52,54-56$ \\
\hline & Spine abnormalities \\
\hline & Kyphoscoliosis $^{49,50}$ \\
\hline & Sacral hemivertebra ${ }^{55}$ \\
\hline & Pubic diastasis ${ }^{51}$ \\
\hline & Missing bladder ${ }^{16,51-54,56}$ \\
\hline & Single umbilical artery ${ }^{16,52,54,55}$ \\
\hline & Abnormality of external genitalia ${ }^{16,54}$ \\
\hline & Hypospadias $^{55}$ \\
\hline & Bifid corporal bodies ${ }^{53}$ \\
\hline & Duplicated vagina, bifid scrotum, micropenis ${ }^{56}$ \\
\hline & Ambiguous genitalia ${ }^{51}$ \\
\hline \multirow[t]{4}{*}{ Case reports } & Intrinsic cardiac abnormalities \\
\hline & Moderate PDA, small PFO, mild tricuspid regurgitation ${ }^{54}$ \\
\hline & ASD, atrioventricular valve, unroofed coronary sinus, persistent L SVC, LVH ${ }^{55}$ \\
\hline & Single right ventricle ${ }^{56}$ \\
\hline \multicolumn{2}{|c|}{ Pentalogy of Cantrell } \\
\hline \multirow[t]{3}{*}{ Diagnostic criteria } & Five distinct criteria, partial cases may have fewer than five \\
\hline & Intracardiac abnormalities \\
\hline & Anterior pericardial defects \\
\hline
\end{tabular}


Table 1 (Continued)

\begin{tabular}{|c|c|}
\hline & Lower sternal defects \\
\hline & Anterior diaphragmatic defects \\
\hline & Supraumbilical abdominal wall defects ${ }^{12}$ \\
\hline \multirow{29}{*}{$\begin{array}{l}\text { Proposed common } \\
\text { findings }\end{array}$} & Ectopia cordis $^{4,8,22,24,26,59}$ \\
\hline & Intrinsic cardiac malformations \\
\hline & $\mathrm{ASD}^{4,26,50}$ \\
\hline & $\mathrm{VSD}^{4,8,24,50}$ \\
\hline & Tetralogy of Fallot $4,22,24,26,50$ \\
\hline & Left ventricular diverticulum ${ }^{26,50}$ \\
\hline & Transposition of the great vessels ${ }^{26}$ \\
\hline & Tricuspid atresia, dextrocardia, anomalous cardiac venous return ${ }^{8}$ \\
\hline & Neural tube defects 26,58 \\
\hline & Midline supraumbilical abdominal wall defect \\
\hline & Omphalocele $4,8,22,26,50,59$ \\
\hline & Diastasis recti abdominis, umbilical hernia, epigastric hernia ${ }^{50}$ \\
\hline & Ventral hernia, open defect ${ }^{26}$ \\
\hline & Supraumbilical hernia ${ }^{24}$ \\
\hline & Sternal defects \\
\hline & Bifid sternum ${ }^{4,26}$ \\
\hline & Cleft sternum $^{4,22,24}$ \\
\hline & Absence of xiphoid ${ }^{8}$ \\
\hline & Split sternum ${ }^{26}$ \\
\hline & Diaphragmatic defects \\
\hline & Anterior diaphragmatic hernia ${ }^{4,24,26,59}$ \\
\hline & Pericardial defects \\
\hline & Pericardial hernia $^{4,50}$ \\
\hline & Absent pericardium ${ }^{26,59}$ \\
\hline & Umbilical cord defects \\
\hline & Single umbilical artery ${ }^{8,22,60}$ \\
\hline & Short cord, hypercoiled cord associated with POC + ectopia cordis $^{8}$ \\
\hline & Facial defects \\
\hline & Cleft lip and/or palate 26 \\
\hline \multirow[t]{6}{*}{ Case reports } & Aplastic left limb ${ }^{61}$ \\
\hline & Spinal defect ${ }^{62}$ \\
\hline & Hypoplastic lung ${ }^{26}$ \\
\hline & ${\text { Bronchopulmonary dysplasia, hypoplastic kidney, cleft lip and palate, pulmonary atresia }{ }^{4}}^{4}$ \\
\hline & Gastroschisis, twin reversed arterial perfusion sequence $^{8}$ \\
\hline & Nonrotation of the midgut, accessory spleen ${ }^{22}$ \\
\hline \multicolumn{2}{|c|}{ Limb-body wall complex } \\
\hline \multirow[t]{5}{*}{ Diagnostic criteria } & Two of the following \\
\hline & Exencephaly or encephalocele with facial clefts \\
\hline & Thoraco- and/or abdominoschisis \\
\hline & Limb defects $^{7,63}$ \\
\hline & Two distinct phenotypes \\
\hline
\end{tabular}


Table 1 (Continued)

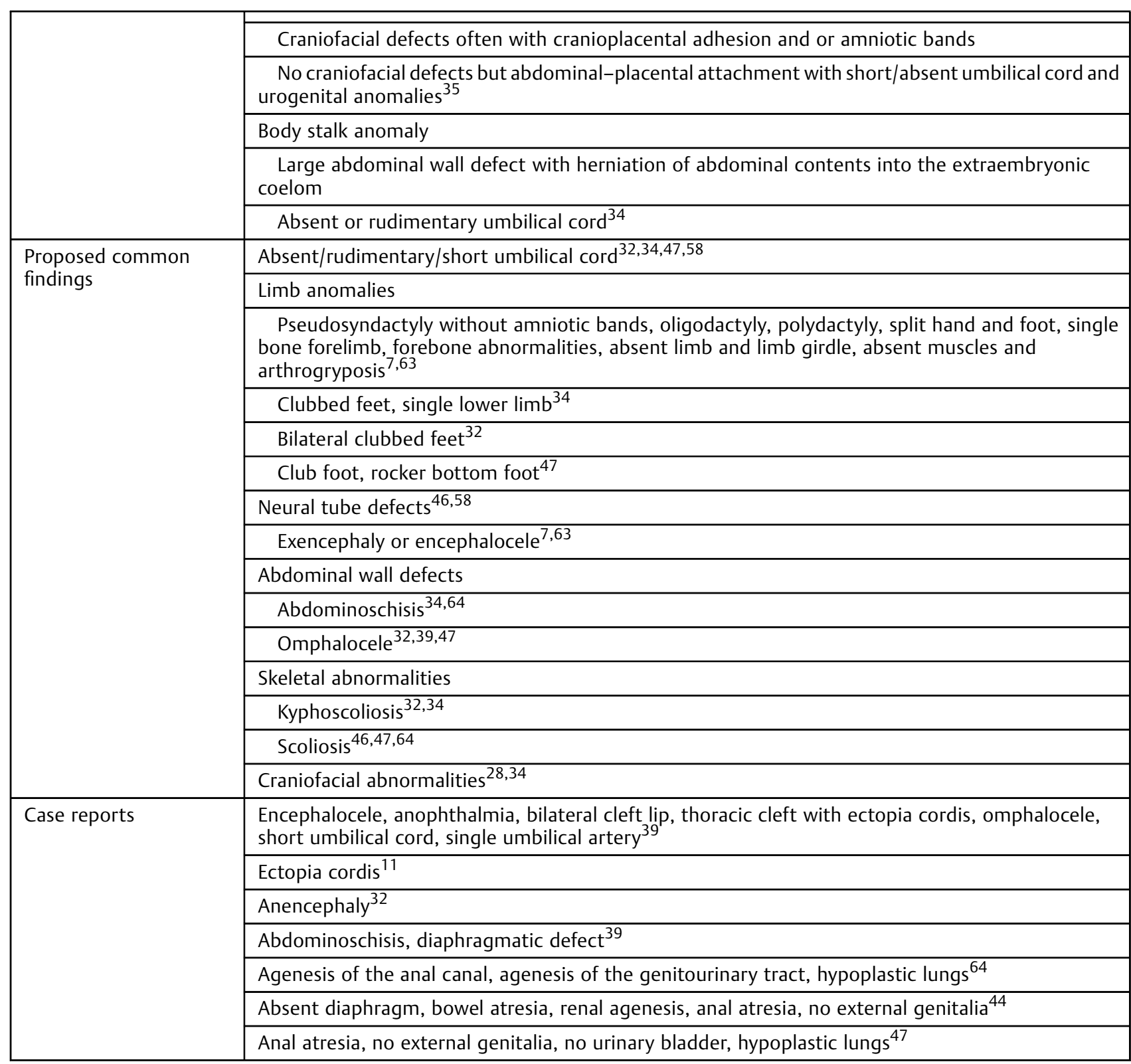

Abbreviations: ASD, atrial septal defect; OEIS, omphalocele, exstrophy, imperforate anus, spina bifida; PDA, patent ductus arteriosus; PFO, patent foramen ovale; SVC, superior vena cava.

surgical repair, surgical diagnosis, pathologic diagnosis, and ultimate disposition are discussed later.

\section{Case 1}

A 35-year-old G4P2012 patient with two prior cesarean sections had a routine prenatal US at $18+4$ weeks at an outside hospital showing multiple congenital anomalies including ventral wall defect. A prenatal MRI was performed at $19+4$ weeks to further refine the diagnosis, and expert US was performed at $29+2$ weeks which showed: (1) a septated cystic structure at fetal sacrum with no Doppler flow, (2) abdominal wall defect containing liver, and (3) empty right renal fossa with a right pelvic kidney. MRI examinations showed: (1) an abdominoschisis containing liver and bowel, (2) pelvic right kidney, (3) splaying of the bladder into hemimasses, (4) sacral myelocystocele, (5) thoracic kyphosis (butterfly vertebra), and (6) hypogenesis of the corpus callosum. Calculated lung volumes were $70 \%$ of predicted and invasive placenta previa was noted. Amniocentesis showed XY with no chromosomal abnormalities and a microarray was normal. Overall, the findings suggested a diagnosis of OEIS, and the patient was counseled accordingly.

Delivery was at $35+5$ weeks via cesarean section, and the neonate had a birth weight of 2,810 g with Apgar scores of 1,1 , and 5 at 1 minute, 5 , and 10 minutes, respectively. There was a three-vessel umbilical cord. Several days after birth, the neonate underwent surgery to tubularize the colon, form an end colostomy, and reapproximate the 


\begin{tabular}{|c|c|c|c|}
\hline & $\begin{array}{c}\text { OEIS } \\
\text { Complex/ } \\
\text { Cloacal } \\
\text { Exstrophy }\end{array}$ & $\begin{array}{c}\text { Limb-Body } \\
\text { Wall Complex/ } \\
\text { Body Stalk } \\
\text { Anomaly }\end{array}$ & $\begin{array}{c}\text { Pentalogy of } \\
\text { Cantrell }\end{array}$ \\
\hline Midline Abdominal Wall Defect & D & D & D \\
\hline Abdominoschisis & D & C & D \\
\hline Neural Tube Defects & D & D & $\mathrm{R}$ \\
\hline Limb Anomalies & C & D & $\mathrm{R}$ \\
\hline Intrinsic Cardiac Abnormality & $\mathrm{R}$ & $\mathrm{R}$ & D \\
\hline Umbilical Cord Defects & c & C & C \\
\hline Normal Karyotype & C & C & C \\
\hline Spine Abnormalities & C & C & $\mathrm{R}$ \\
\hline Kidney Malformation & C & $\mathrm{R}$ & $\mathrm{R}$ \\
\hline Imperforate Anus & D & $\mathrm{R}$ & \\
\hline Missing Bladder & D & R & \\
\hline Abnormality of External Genitalia & C & R & \\
\hline Diaphragm Defects & & $\mathrm{R}$ & D \\
\hline Pericardial Defects & & $\mathrm{R}$ & D \\
\hline Sternal Defects & & $\mathrm{R}$ & D \\
\hline Ectopia Cordis & & $\mathrm{R}$ & C \\
\hline Feto-Placental Attachment & & D & C \\
\hline Cleft Lip and/or Palate & & D & $\mathrm{R}$ \\
\hline $\mathrm{D}=$ Diagnostic Criteria & $\mathrm{C}=$ Commonly & \multicolumn{2}{|c|}{ R = Case Reports Include } \\
\hline
\end{tabular}

Fig. 1 Overlap of findings for OEIS complex/cloacal exstrophy, limb-body wall complex/body stalk anomaly, and pentalogy of Cantrell graphically represented. OEIS, omphalocele, exstrophy, imperforate anus, spina bifida. 
bladder halves. At that time, the patient was noted to have a short colonic segment with two appendices, giant abdominoschisis, and pelvic findings of OEIS. The patient spent time admitted to the neonatal intensive care unit (NICU) and had a recovery complicated by return to the operating room for resection of a bowel stricture. The patient remains alive.

\section{Case 2}

A 29-year-old G3P2 patient with a history of preterm labor had routine prenatal US showing ventral wall defect, which led to prenatal MRI at $28+2$ weeks (-Fig. 2) showing: (1) giant abdominoschisis with fusion of the hernia sac to the placenta, (2) covered lumbosacral myelomeningocele, (3) unilateral renal agenesis, (4) nonvisualized bladder with "elephant trunk" appearance of the ileum between hemibladder masses, (5) narrow thoracic cavity, (6) focal scoliosis with hemivertebra, (7) a shortened umbilical cord, (8) suspected hypoplastic sternum, (9) small defect in the anterior left hemidiaphragm and potentially in the diaphragmatic pericardium with inferior displacement of the heart, (10) complete absence of the right lower extremity, and (11) hypoplastic left foot and partial amputation of the left tibia.
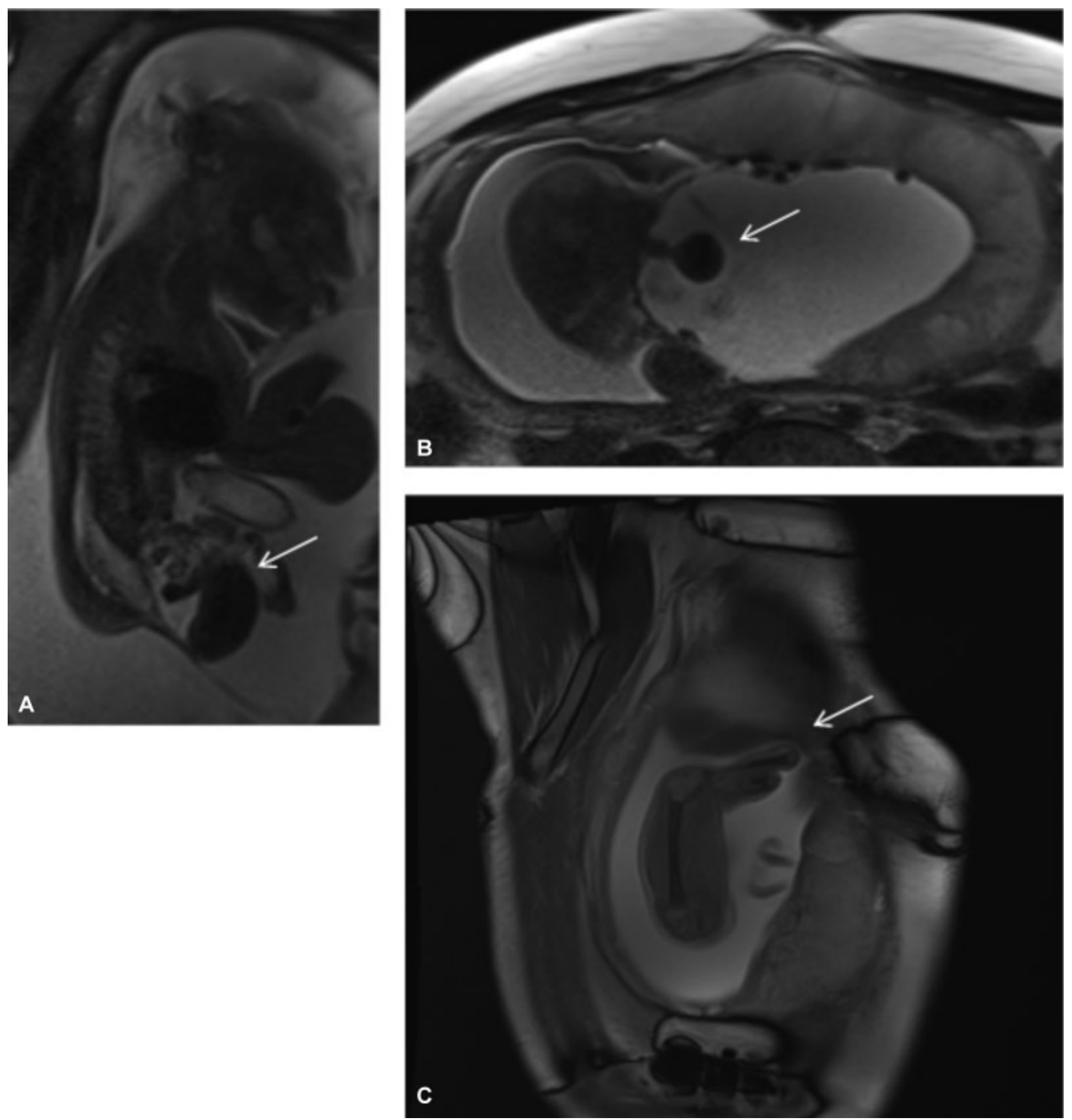

Fig. 2 Case 2 sagittal (A, C) and axial (B) SSFSE MRIs. (A, B) No fluid-filled bladder, with "elephant trunk" midline loop of bowel and lateralized hemibladder masses. (C) Amputated lower limb in patient with myelomeningocele and nonvisualized bladder. MRI, magnetic resonance imaging; SSFSE, single-shot fast spin-echo. 
Calculated lung volumes were $40 \%$ of predicted. The patient was referred to our fetal center, and expert prenatal US at $31+1$ weeks showed similar findings including: (1) abdominoschisis with membrane adherent to the placenta, (2) a majority of the abdominal contents herniating through the defect, (3) absent right lower extremity and hemipelvis, (4) abnormalities of the distal bones of the left lower extremity, (5) a closed myelomeningocele, and (6) nonvisualized bladder and genitalia. Cell-free DNA analysis suggested a male fetus with low risk for aneuploidy. Given the highly complex and varied findings, and especially given the pulmonary hypoplasia, the patient was counseled that the prognosis was guarded.

Delivery was at $33+4$ weeks via emergent cesarean section at an outside hospital due to premature labor. The neonate was unable to be adequately ventilated, and died at 6 hours after birth secondary to extreme metabolic and respiratory acidosis. An autopsy was not performed.

\section{Case 3}

A 32-year-old G2P0101 patient with hypothyroidism and history of preterm premature rupture of membranes was referred to our center for ventral wall defect, and received expert prenatal US at $29+3$ weeks which showed: (1) splayed lower spine with intact skin, (2) bilateral talipes equinovarus, (3) nonvisualized bladder, and (4) two-vessel cord. Follow-up prenatal MRI at $31+5$ weeks showed: (1) infraumbilical abdominoschisis, (2) nonvisualized bladder with hemibladder masses externally, (3) poorly formed external genitalia, (4) lumbosacral myelomeningocele, (5) bilateral talipes equinovarus deformity, and (6) two-vessel cord. The patient did not desire genetic testing. The constellation of findings was most suggestive of OEIS, and the patient was counseled accordingly.

Delivery was at $35+4$ weeks via urgent cesarean section for breech position and preterm labor. The male neonate was transferred to the NICU. At several days of life, the neonate underwent surgery to form an ostomy and reapproximate the bladder halves. Repair of the lipomyelomeningocele and tethered cord was conducted months later. Bilateral pelvic osteotomies with additional iliac closing wedge were done at 13 months of age and surgery to form an ileovesicostomy was done at 14 months of age. The infant is currently alive and continues follow-up in the urology and spina bifida clinics.

\section{Case 4}

A 28-year-old G2P1001 patient had a routine prenatal US at $18+0$ weeks which showed: (1) a ventral wall defect with liver and bowel extrusion, (2) nonvisualized bladder, (3) possible early ectopia cordis with a structural cardiac abnormality, (4) short umbilical cord which traveled directly from the anterior placenta to the herniated organs, (5) motion of fetal extremities but not of the fetal body, (6) scoliosis, and (7) a right talipes equinovarus deformity. A prenatal MRI at $28+5$ weeks showed: (1) nonvisualized bladder with "elephant trunk" appearance of the ileum between hemibladder masses, (2) infraumbilical abdominoschisis with fusion of the hernia sac to the placenta, (3) lumbosacral myelomeningocele with scoliosis, (4) a right talipes equinovarus deformity, (5) narrowed thoracic cavity, and (6) single umbilical artery with a shortened cord and anomalous fetal insertion (wide separation of the vessels prior to entering the fetal abdominal cavity). Calculated lung volumes were $25 \%$ of predicted. Cell-free DNA testing suggested a female fetus with low risk for aneuploidy. Given the highly complex and varied findings, including features of POC, OEIS, and LBWC, and especially given the pulmonary hypoplasia, the patient was counseled that the prognosis was likely to be poor.

Delivery was at $32+0$ weeks via classical cesarean section for preterm labor, with damage to the ventral hernia sac membrane occurring during delivery, as expected. At immediate neonatal surgical repair, the patient was found to have a large abdominoschisis with exstrophy of bladder and a myelomeningocele covered with skin. She was difficult to ventilate after delivery. A decision for comfort care was made after 6 hours of life and death occurred shortly thereafter. No autopsy was performed.

\section{Case 5}

A 25-year-old G2P1 patient with no significant past medical history had a prenatal US at an outside center at $19+6$ weeks which showed an abdominal wall mass and possible neural tube defect. A prenatal MRI at $22+5$ weeks showed: (1) an abdominoschisis containing the liver, (2) two-vessel umbilical cord, (3) nonvisualized urinary bladder with hemibladder masses, (4) abnormal male external genitalia, (5) lumbar myelomeningocele, and (6) right renal agenesis. Cellfree DNA testing suggested a male fetus with no other abnormalities. These features were thought to be most compatible with OEIS, and the patient was counseled accordingly. However the pregnancy ended with fetal demise in the second trimester, with delivery at an outside center.

\section{Case 6}

A 31-year-old G3P1111 patient had a routine prenatal US at outside center, which showed VBWD. She presented to our center at $24+6$ weeks and prenatal MRI was performed (-Fig. 3), showing: (1) abdominoschisis, (2) myelomeningocele, (3) severe scoliosis, (4) talipes equinovarus deformity bilaterally, (5) short umbilical cord, and (6) small thoracic cavity. A second MRI at $28+5$ weeks redemonstrated the small thoracic cavity. Calculated lung volumes were $17 \%$ of predicted. Karyotype from amniocentesis showed XY with no other additional studies ordered. Given these findings, the patient was counseled regarding OEIS as the most likely diagnosis, and given the severe pulmonary hypoplasia, was told that prognosis was poor. The pregnancy ended with fetal demise in the third trimester, with delivery at an outside center.

\section{Case 7}

A 24-year-old G1P0 patient with sickle cell trait had a ventral defect found on outside routine prenatal US and underwent prenatal MRI at $21+0$ weeks which showed: (1) supraumbilical abdominoschisis, (2) suspected mild defect of the 

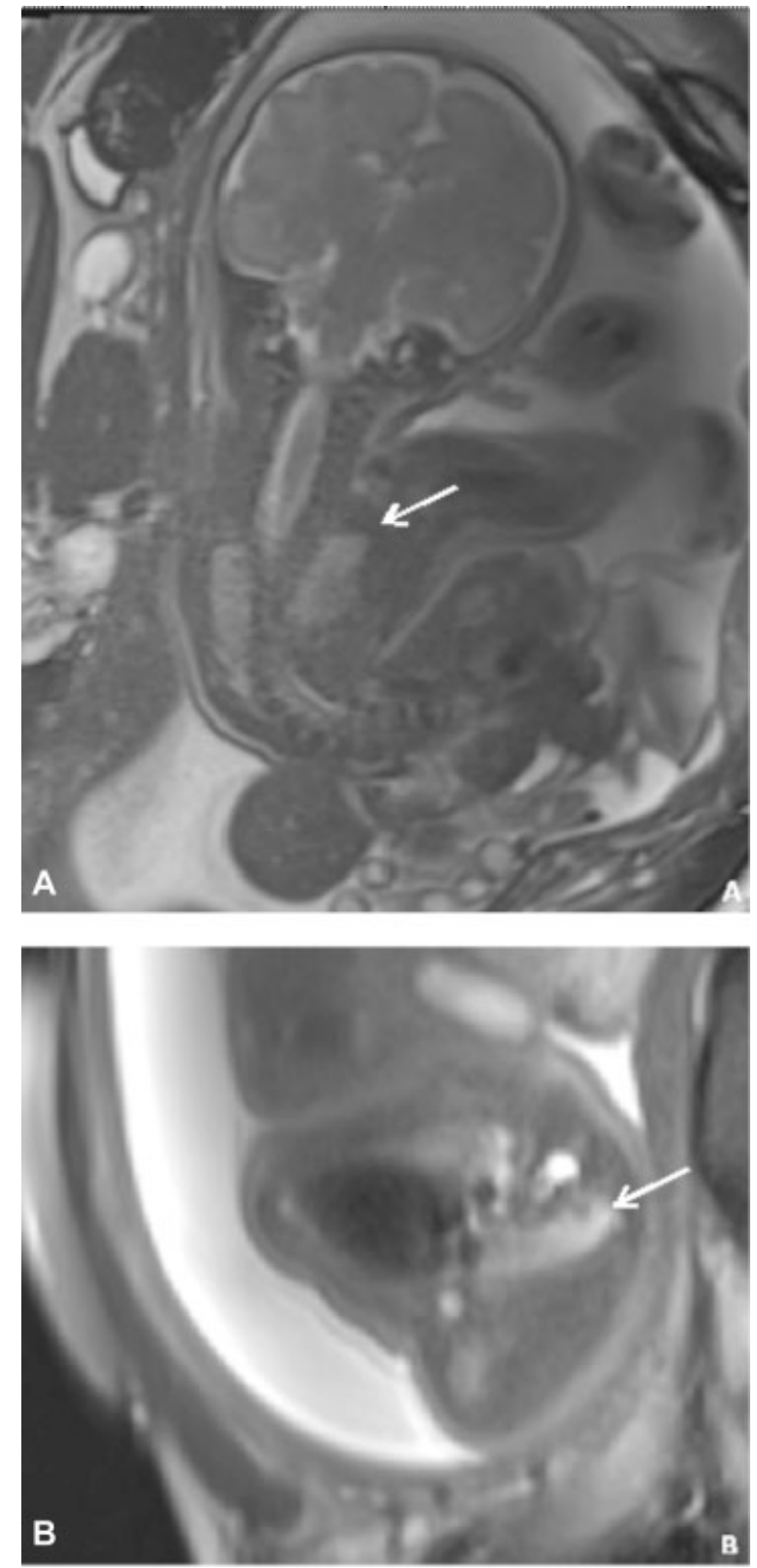

Fig. 3 Case 6 coronal (A) and axial (B) SSFSE MRIs. (A, B) Scoliosis and severely narrowed thoracic cavity, with pulmonary hypoplasia. MRI, magnetic resonance imaging; SSFSE, single-shot fast spin-echo.

anterior diaphragm and lower sternum/chest wall, and (3) small thoracic cavity. Calculated lung volumes were $65 \%$ of predicted. An expert prenatal US at $25+3$ weeks showed: (1) abdominoschisis with liver herniation and (2) malposition of the cardiac apex abnormally anterior in position. No genetic testing was desired. At the time of this case study, the fetus is not yet delivered.

\section{Discussion}

One of the earliest published reports of cloacal exstrophy was made in the late 19th century by an Italian teratologist, Dr. C. Taruffi, who also referenced ancient descriptions of perineal congenital anomalies. ${ }^{14}$ In 1978, Carey et al published a case series of 10 patients, the largest to that date, suggesting the name "OEIS complex," as a simple and accurate moniker. ${ }^{11}$ Importantly, this article proposed that "OEIS complex is a distinct and clinically recognizable entity of heterogeneous etiology." 11 Indeed, OEISs represented the consistent findings among the cases, but other malformations, such as clubfoot and ambiguous genitalia, were also reported. In a 2001 editorial, Carey clarified OEIS complex and cloacal exstrophy are meant to be synonymous. ${ }^{3}$ In 1992 , a case report from Smith et al asserted OEIS may be the worst form of the exstrophy-epispadias sequence but provided no citation for this claim. ${ }^{6}$ In 1998, Austin et al proposed a set of diagnostic criteria for US, based heavily on the initial observations of Carey et al and moving OEIS from a postnatal to a prenatal diagnosis. ${ }^{10}$ They suggested the following major criteria: nonvisualization of the bladder, a large midline infraumbilical anterior wall defect or cystic anterior wall structure (persistent cloacal membrane), abdominoschisis, and lumbosacral anomalies, and minor criteria: lower extremity defects, renal anomalies, ascites, widened pubic arches, a narrow thorax, hydrocephalus, and a single umbilical artery. ${ }^{10}$ In 1999, Hamada et al suggested the midline prolapsed ileum visualized on US between the hemibladder masses, termed the "elephant trunk sign," should be added to Austin et al's sonographic diagnostic criteria. ${ }^{15}$ Calvo-Garcia et al reported a case series of eight patients with cloacal exstrophy suggesting fetal MRI to be useful in the prenatal diagnostic algorithm when US is inconclusive. ${ }^{16}$ They also identified specific fetal MRI findings contributing to the diagnosis of cloacal exstrophy. ${ }^{17}$

Much of the literature on OEIS is found in urologic journals because these defects are typically repaired and patients are followed up by pediatric urologists. The oft-quoted incidence of OEIS, 1 in 200,000 live births originates in a 1970 five case series with review of cases to date. ${ }^{18}$ The incidence of 1 in 400,000 births is from an extrapolation of the rate of bladder exstrophy and relative proportions of vesical exstrophy complex of anomalies in $1986 .{ }^{19}$ These incidences have been questioned in case reports. ${ }^{13}$ Recently, a 2011 epidemiologic study from the International Clearinghouse for Birth Defects Surveillance and Research suggested an overall prevalence of 1 in 131,579 with variance by country. ${ }^{20} \mathrm{~A}$ survival rate of up to $90 \%$ was first reported in a series of 34 patients spanning 1963 to 1986 and published in $1987 .^{21}$

POC was first described by Cantrell et al in a 1958 case series of five patients linked to an additional 16 previously published case reports. ${ }^{12}$ In it, they described a syndrome of congenital defects: midline supraumbilical abdominoschisis, lower sternal defect, deficiency of the anterior diaphragm, deficiency of the diaphragmatic pericardium, and intracardiac abnormalities. These constitute the five findings necessary for a diagnosis. Notably, ectopia cordis is not necessary for diagnosis but is often seen in POC and is considered a poor prognostic factor. ${ }^{4,22}$ In 1972, Toyama published a case report and review of 60 purported cases of POC, in which they suggest diagnosing incomplete expression as a variant of the syndrome. ${ }^{5}$ Thus, a neonate with partial POC may present with only two, three, or four of the necessary five 
defects. In 1998, Vazquez-Jimenez et al conducted an extensive review of the literature, compiling 153 purported cases of POC and reviewing the spectrum of malformations. ${ }^{23} \mathrm{US}$, the mainstay of prenatal imaging, is most frequently used to assist in the diagnosis of POC.22,24 Siles et al noted that pericardial effusion was a helpful indicator of a pericardial defect in a three case series of POC. ${ }^{25}$ In 2007, McMahon et al reported the use of combined fetal MRI and fetal echocardiography to guide prenatal planning. ${ }^{24}$ US was considered more useful than MRI for assessing sternal and pericardial defects. The incidence of POC, which has been quoted at 5.5 in 1 million live births, was first estimated in a case series of five patients from a population in the Baltimore-Washington, DC region of the United States. ${ }^{26}$ The authors qualified this incidence as a regional estimate. Other descriptions in the literature suggest estimates ranging from 1 in 6,500 to 1 in 200,000 births. ${ }^{22}$ The latter is derived from the 5.5 in 1 million estimate, while the former originates from a Finnish group who assumed seven cases in 7 years represented the total live birth incidence of POC in Finland. ${ }^{27}$

LBWC was first reported in the European literature at the start of the 20th century. Van Allen et al are widely cited as the first to put forward discrete diagnostic criteria for LBWC in a case series of 25 , published in $1987 .{ }^{7}$ They based their diagnosis on two of the three following findings: (1) exencephaly or encephalocele with facial clefts, (2) thoraco- and/ or abdominoschisis, and (3) limb defect. Initially, LBWC was regarding as distinct from a similar diagnosis, BSA. Embryologically, the "body stalk" is seen early in development, connecting the embryo to the placenta in early life and is composed of extraembryonic somatic mesoderm and the three umbilical vessels. ${ }^{28}$ Abnormal persistence of this connection has been termed "BSA," and in a 1992 case report, Giacoia suggested absence of the umbilical cord and fusion of the organ containing membranous sac to the placenta as key findings in BSA. ${ }^{29}$ Although not clear in the literature as to when, at some point many authors began to assert that LBWC was equivalent with BSA. ${ }^{30-33}$ Other sources state that these are distinct entities on the same spectrum, and some have presented criteria on how to differentiate the two. Namely, BSA will not have extremity defects. ${ }^{34}$

In 1993, based on a review of current literature, Russo et al suggested LBWC presents with two distinct phenotypes. In this description, the first has two specific findings: (1) encephalocele or exencephaly, always associated with facial cleft, and (2) amniotic bands and or broad amniotic adhesion between the cranial defect and the placenta. The second phenotype will not have the aforementioned findings, but often presents with (1) urogenital anomalies, (2) anal atresia, (3) lumbosacral meningocele, and (4) placental abnormalities such as an intact amnion, short cord, and persistence of the extraembryonic coelom. ${ }^{35}$ This nomenclature has been invoked as a valid method to classify LBWC defects by multiple subsequent authors. US is frequently cited as an effective prenatal diagnostic modality for this condition, ${ }^{28,30,32-34}$ and Sahinoglu et al put forth sonographic criteria for three phenotypes of LBWC based on a case series of six. ${ }^{36}$ Recently, Aguirre-Pascual et al noted fetal MRI to be useful as an adjunct diagnostic modality to US in the prenatal characterization of LBWC. ${ }^{37}$ LBWC has also been included as one manifestation of the amniotic band sequence, an idea first proposed by Torpin in $1965 .^{38,39}$ However, in 1989, a case series of four by Hartwig et al challenged this relationship, saying that malformations of LBWC are better explained by a malfunction in the ectodermal placodes. ${ }^{40}$ Recently, Moerman et al argued that amniotic band sequence and LBWC represent discrete entities which have pathogenic overlap as opposed to spectrums of the same disease. ${ }^{41}$ Given the large number of cases with normal karyotype, many authors have proposed a multiple hit phenomenon. ${ }^{42,43}$ However, in 2011, Hunter et al described an overview of the many diverse theories and made a case for a primary mechanism. ${ }^{43}$ LBWC is considered by most authors to be uniformly fatal with a purported incidence of 1 in 4,000 , though no source is given for this. ${ }^{44}$

The precise pathogenesis of these three entities remains unknown, though frequently debated. Many theories have been proposed but none has been validated. Many of the case reports in the literature contain, within a single patient, features from two or more of these diagnoses or overlapping features from multiple diagnoses. Given this, some have proposed that these conditions are less likely to be distinct diagnostic categories with unique pathophysiologic mechanisms, but rather more likely to represent multiple points along a continuous spectrum. This would also mirror proposals by Smrcek et al and Hunter et al who each suggested that the numerous manifestations of VBWD are likely to reflect variations of aberrant cephalic, caudal, and/ or lateral folding, thus giving rise to subsequent patterns of maldevelopment. $^{30,43}$

As a clear example, consider the following two sets of criteria which have been asserted as diagnostic of OEIS and type 2 LBWC (-Table 2). OEIS is described as omphalocele/ exstrophy of the bladder/imperforate anus/spina bifida, while type 2 LBWC is described as abdominoschisis/urogenital anomalies/anal atresia/lumbosacral meningocele.

The remarkable similarity of these two sets of criteria confuses the diagnostic process. Of even greater concern is that the published mortality rates of these two conditions are incredibly divergent, frequently reported as $\sim 10 \%$ for OEIS, and as $100 \%$ for LBWC. ${ }^{2,21}$ For expectant families, such a wide range of supposed outcomes severely limits the ability of the perinatal care team to provide proper counseling.

Table 2 Comparison of diagnostic criteria for OEIS complex and type 2 LBWC

\begin{tabular}{|l|l|}
\hline OEIS complex & \\
\hline Omphalocele & Type 2 LBWC $^{35}$ \\
\hline Exstrophy of the bladder & Abdominoschisis \\
\hline Imperforate anus & Urogenital anomalies \\
\hline Spina bifida & Anal atresia \\
\hline
\end{tabular}

Abbreviations: LBWC, limb-body wall complex; OEIS, omphalocele, exstrophy, imperforate anus, spina bifida. 
Our case series and review of the literature demonstrate that it can be extremely challenging to fit a newly diagnosed fetal VBWD into the existing diagnostic categories. Numerous reported cases of VBWD (-Fig. 4), rather than fitting completely into one of the traditional diagnostic silos, instead span across more than one of these diagnoses. $^{31,42,45-48}$ In our own cohort, six of the seven complicated VBWD cases encountered over a 24-month period demonstrated just such a hybrid constellation of findings. The traditional diagnostic categories may obscure more than they reveal.

We believe that the current paradigm depends too heavily on creating distinctions, when many cases seem to fall somewhere between two or more of the traditional diagnostic categories. This is especially clear given the published literature on this topic is far from uniform agreement. Perhaps most importantly, we need to consider what approach would be most clinically relevant.

Further, although many of the patients in our cohort exhibited diverse findings related to multiple diagnoses, six of the seven had findings that correlated well with the diagnostic criteria for cloacal exstrophy/OEIS. Given the published incidence of around 1 in 200,000 live births, this would mean that six cases in 24 months would represent a startlingly high rate to a region in the United States which has a total of around 30,000 deliveries annually. An alternative
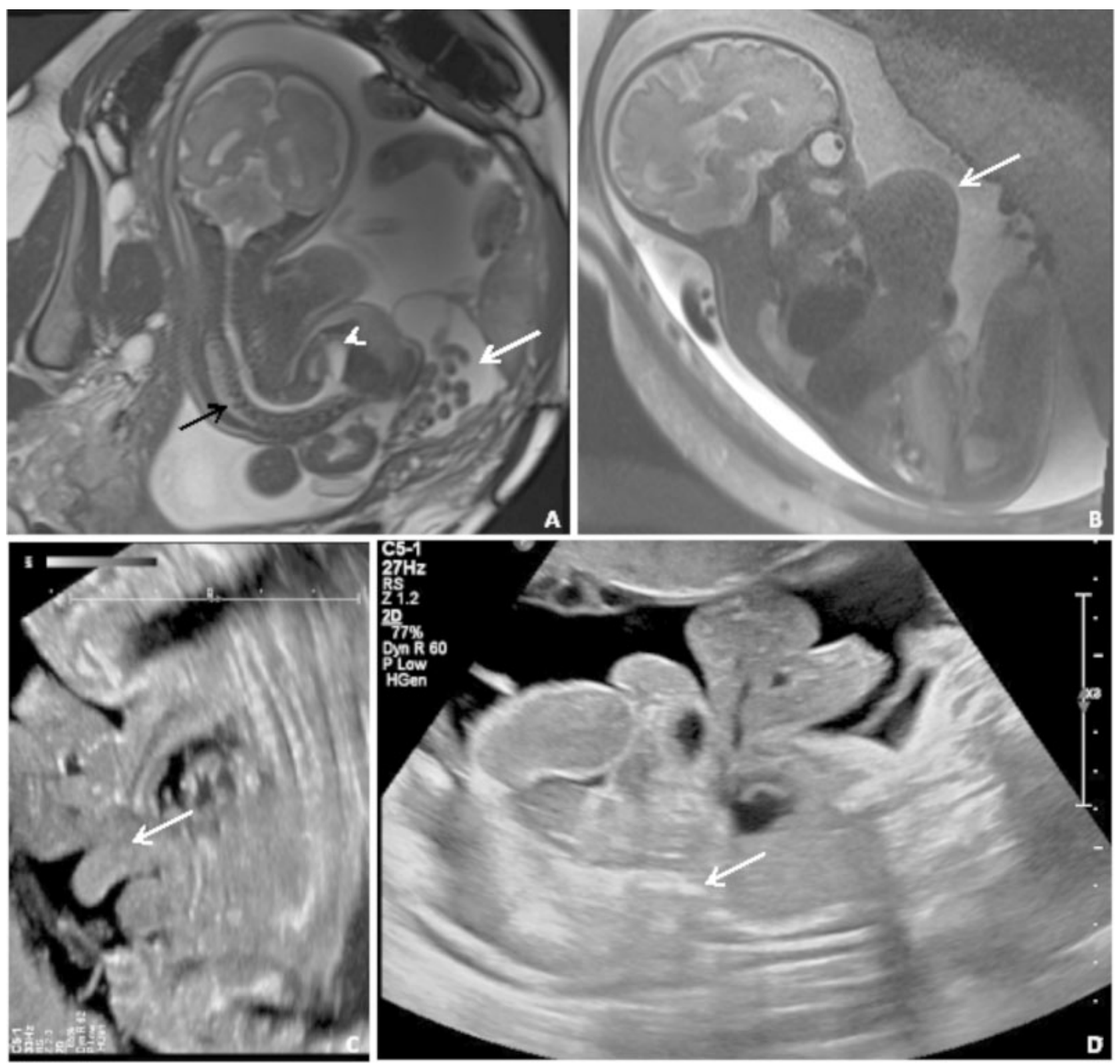

Fig. 4 Coronal SSFP (A) and sagittal SSFSE (B) MRIs and two transabdominal ultrasound images of several older cases from our center. (A) Severe scoliosis (black arrow), abdominoschisis (white arrow), and meningocele (short arrow), but without body wall fusion. (B) Supraumbilical defect (white arrow) and absent bladder. (C) "Elephant trunk" sign representing prolapsed terminal ileum. (D) Fetal fusion to the placenta (white arrow) with large abdominoschisis. MRI, magnetic resonance imaging; SSFP, steady-state free precession; SSFSE, single-shot fast spin-echo. 
interpretation would be to recognize multiple of the cases in our cohort as hybrid, and not as completely representative of classic OEIS.

More importantly, we found that outcomes correlated much more closely with pulmonary development. In our recent cohort, the prenatal identification of pulmonary hypoplasia was quite useful, given that our two survivors (cases 1 and 3 ) had no documented hypoplasia on prenatal imaging, and three of the four patients who died (cases 2, 4, and 6 ) had pulmonary hypoplasia with lung volumes ranging from 17 to $40 \%$ of expected.

The size of our patient cohort and the relative infrequency of many of the diagnoses discussed here is a limitation of this review and analysis. Further, there are inherent limitations to any analysis of prenatal diagnosis of VBWD given the lack of diagnostic consensus in the literature, unknown etiology, and absence of confirmatory testing.

\section{Conclusion}

Our experience with these complex cases of VBWD reveals that they are most appropriately understood as existing along a spectrum of anomalies arising from failure of the lateral and craniocaudal folds to close appropriately early in gestation. Further, our analysis of the published literature on this topic demonstrates no clear consensus on how to optimally diagnose those cases which straddle the traditional diagnostic categories of OEIS/cloacal exstrophy, LBWD/BSA, and POC.

We propose a prenatal diagnostic process that values prognostication and planning over classification. Key objectives of prenatal diagnosis are to appropriately counsel families, plan for safe delivery, and direct immediate neonatal management. Any diagnostic categorization should be at the service of these goals.

At best, a rigid dependence on formal categories can lead to a confusing misnaming of disease, but at worst, it can result in serious prognostic inaccuracies and lead to increased distress for families seeking care. As an alternative, we call for the development of a more descriptive diagnostic approach, depending on type and volume of organ herniation, degree of pulmonary hypoplasia, and presence of head, body, or hernia membrane fusion to the placenta. Future prospective studies will be needed to further elucidate what imaging findings are most predictive of outcome.

\section{Note}

No funding sources supported this work. The authors have no disclosure.

\section{References}

1 Feldkamp ML, Botto LD, Byrne JLB, Krikov S, Carey JC. Clinical presentation and survival in a population-based cohort of infants with gastroschisis in Utah, 1997-2011. Am J Med Genet A 2016; 170A(02):306-315
2 Emanuel PG, Garcia GI, Angtuaco TL. Prenatal detection of anterior abdominal wall defects with US. Radiographics 1995;15(03): 517-530

3 Carey JC. Exstrophy of the cloaca and the OEIS complex: one and the same. Am J Med Genet 2001;99(04):270

4 Kaul B, Sheikh F, Zamora IJ, et al. 5, 4, 3, 2, 1: embryologic variants of pentalogy of Cantrell. J Surg Res 2015;199(01):141-148

5 Toyama WM. Combined congenital defects of the anterior abdominal wall, sternum, diaphragm, pericardium, and heart: a case report and review of the syndrome. Pediatrics 1972;50(05): 778-792

6 Smith NM, Chambers HM, Furness ME, Haan EA. The OEIS complex (omphalocele-exstrophy-imperforate anus-spinal defects): recurrence in sibs. J Med Genet 1992;29(10):730-732

7 Van Allen MI, Curry C, Gallagher L. Limb body wall complex: I. Pathogenesis. Am J Med Genet 1987;28(03):529-548

8 Brochut A-CM, Baumann MU, Kuhn A, et al. Pentalogy or hexalogy of Cantrell? Pediatr Dev Pathol 2011;14(05):396-401

9 Ueda H, Miyamoto T, Minase G, Sengoku K. Prenatal diagnosis of a body stalk anomaly by a combination of ultrasonography and foetal magnetic resonance imaging. J Obstet Gynaecol 2017;37 (07):946-947

10 Austin PF, Homsy YL, Gearhart JP, et al. The prenatal diagnosis of cloacal exstrophy. J Urol 1998;160(3 Pt 2):1179-1181

11 Carey JC, Greenbaum B, Hall BD. The OEIS complex (omphalocele, exstrophy, imperforate anus, spinal defects). Birth Defects Orig Artic Ser 1978;14(6B):253-263

12 Cantrell JR, Haller JA, Ravitch MM. A syndrome of congenital defects involving the abdominal wall, sternum, diaphragm, pericardium, and heart. Surg Gynecol Obstet 1958;107(05):602-614

13 Keppler-Noreuil K, Gorton S, Foo F, Yankowitz J, Keegan C. Prenatal ascertainment of OEIS complex/cloacal exstrophy - 15 new cases and literature review. Am J Med Genet A 2007;143A(18): 2122-2128

14 Taruffi C. Storia Della Teratologia. Vol 7. Bologna, Italy: Regia Tipografia; 1894

15 Hamada H, Takano K, Shiina H, Sakai T, Sohda S, Kubo T. New ultrasonographic criterion for the prenatal diagnosis of cloacal exstrophy: elephant trunk-like image. J Urol 1999;162(06): 2123-2124

16 Calvo-Garcia MA, Kline-Fath BM, Rubio EI, Merrow AC, Guimaraes CV, Lim F-Y. Fetal MRI of cloacal exstrophy. Pediatr Radiol 2013;43 (05):593-604

17 Calvo-Garcia MA, Kline-Fath BM, Levitt MA, et al. Fetal MRI clues to diagnose cloacal malformations. Pediatr Radiol 2011;41(09): $1117-1128$

18 Tank ES, Lindenauer SM. Principles of management of exstrophy of the cloaca. Am J Surg 1970;119(01):95-98

19 Ziegler M, Duckett J, Howell C. Cloacal exstrophy. In: Welch K, Randolph J, Ravtich M, O'Neil J, Rowe M, eds. Pediatric Surgery. Chicago: Year Book Medical Publishers; 1986:764-771

20 Feldkamp ML, Botto LD, Amar E, et al. Cloacal exstrophy: an epidemiologic study from the International Clearinghouse for Birth Defects Surveillance and Research. Am J Med Genet C Semin Med Genet 2011;157C(04):333-343

21 Hurwitz RS, Manzoni GA, Ransley PG, Stephens FD. Cloacal exstrophy: a report of 34 cases. J Urol 1987;138(4 Pt 2):1060-1064

22 Desselle C, Herve P, Toutain A, Lardy H, Sembely C, Perrotin F. Pentalogy of Cantrell: sonographic assessment. J Clin Ultrasound 2007;35(04):216-220

23 Vazquez-Jimenez JF, Muehler EG, Daebritz S, et al. Cantrell's syndrome: a challenge to the surgeon. Ann Thorac Surg 1998; 65(04):1178-1185

24 McMahon CJ, Taylor MD, Cassady CI, Olutoye OO, Bezold LI. Diagnosis of pentalogy of Cantrell in the fetus using magnetic resonance imaging and ultrasound. Pediatr Cardiol 2007;28(03): 172-175 
25 Siles C, Boyd PA, Manning N, Tsang T, Chamberlain P. Omphalocele and pericardial effusion: possible sonographic markers for the pentalogy of Cantrell or its variants. Obstet Gynecol 1996;87(5 Pt 2):840-842

26 Carmi R, Boughman JA. Pentalogy of Cantrell and associated midline anomalies: a possible ventral midline developmental field. Am J Med Genet 1992;42(01):90-95

27 Vanamo K, Sairanen H, Louhimo I. The spectrum of Cantrell's syndrome. Pediatr Surg Int 1991;6(06):429-433

28 Goldstein I, Winn HN, Hobbins JC. Prenatal diagnostic criteria for body stalk anomaly. Am J Perinatol 1989;6(01):84-85

29 Giacoia GP. Body stalk anomaly: congenital absence of the umbilical cord. Obstet Gynecol 1992;80(3 Pt 2):527-529

30 Smrcek JM, Germer U, Krokowski M, et al. Prenatal ultrasound diagnosis and management of body stalk anomaly: analysis of nine singleton and two multiple pregnancies. Ultrasound Obstet Gynecol 2003;21(04):322-328

31 Mandrekar SRS, Amoncar S, Banaulikar S, Sawant V, Pinto RGW. Omphalocele, exstrophy of cloaca, imperforate anus and spinal defect (OEIS complex) with overlapping features of body stalk anomaly (limb body wall complex). Indian J Hum Genet 2014;20 (02):195-198

32 Kocherla K, Kumari V, Kocherla PR. Prenatal diagnosis of body stalk complex: a rare entity and review of literature. Indian J Radiol Imaging 2015;25(01):67-70

33 Bhat A, Ilyas M, Dev G. Prenatal sonographic diagnosis of limbbody wall complex: case series of a rare congenital anomaly. Radiol Case Rep 2016;11(02):116-120

34 Murphy A, Platt LD. First-trimester diagnosis of body stalk anomaly using 2- and 3-dimensional sonography. J Ultrasound Med 2011;30(12):1739-1743

35 Russo R, D’Armiento M, Angrisani P, Vecchione R. Limb body wall complex: a critical review and a nosological proposal. Am J Med Genet 1993;47(06):893-900

36 Sahinoglu Z, Uludogan M, Arik H, et al. Prenatal ultrasonographical features of limb body wall complex: a review of etiopathogenesis and a new classification. Fetal Pediatr Pathol 2007;26(03): 135-151

37 Aguirre-Pascual E, Epelman M, Johnson AM, Chauvin NA, Coleman BG, Victoria T. Prenatal MRI evaluation of limb-body wall complex. Pediatr Radiol 2014;44(11):1412-1420

38 Torpin R. Amniochorionic mesoblastic fibrous strings and amniotic bands: associated constricting fetal malformations or fetal death. Am J Obstet Gynecol 1965;91:65-75

39 Zeidler S, Oudesluijs GG, Schoonderwaldt EM, Van Bever Y. Early prenatal disruption; a foetus with features of severe limb body wall sequence, body stalk anomaly and amniotic bands. Genet Couns 2014;25(03):315-320

40 Hartwig NG, Vermeij-Keers C, De Vries HE, Kagie M, Kragt H. Limb body wall malformation complex: an embryologic etiology? Hum Pathol 1989;20(11):1071-1077

41 Moerman P, Fryns JP, Vandenberghe K, Lauweryns JM. Constrictive amniotic bands, amniotic adhesions, and limb-body wall complex: discrete disruption sequences with pathogenetic overlap. Am J Med Genet 1992;42(04):470-479

42 Heyroth-Griffis CA, Weaver DD, Faught P, Bellus GA, TorresMartinez W. On the spectrum of limb-body wall complex, exstrophy of the cloaca, and urorectal septum malformation sequence. Am J Med Genet A 2007;143A(10):1025-1031

43 Hunter AGW, Seaver LH, Stevenson RE. Limb-body wall defect. Is there a defensible hypothesis and can it explain all the associated anomalies? Am J Med Genet A 2011;155A(09):2045-2059

44 D'Souza J, Indrajit IK, Menon S. Limb body wall complex. Med J Armed Forces India 2004;60(01):77-80
45 Kunapinun N, Treetipsatit J. Discordant anomalies with combined features of pentalogy of Cantrell and OEIS complex: a case report in monochorionic twins. Fetal Pediatr Pathol 2017;36(05): 357-363

46 Vujovic D, Sretenovic A, Raicevic M, et al. Thoracoschisis associated with limb body wall complex. APSP J Case Rep 2017;8(03): 19

47 Prasun P, Behera BK, Pradhan M. Limb body wall complex. Indian J Pathol Microbiol 2008;51(02):255-256

48 Bijok J, Massalska D, Kucińska-Chahwan A, et al. Complex malformations involving the fetal body wall - definition and classification issues. Prenat Diagn 2017;37(10):1033-1039

49 Chauvin NA, Epelman M, Victoria T, Johnson AM. Complex genitourinary abnormalities on fetal MRI: imaging findings and approach to diagnosis. AJR Am J Roentgenol 2012;199(02):W22231

50 Torres US, Portela-Oliveira E, Braga FdelC, Werner H Jr, Daltro PAN Souza AS. When closure fails: what the radiologist needs to know about the embryology, anatomy, and prenatal imaging of ventral body wall defects. Semin Ultrasound CT MR 2015;36(06):522-536

51 Gobbi D, Fascetti Leon F, Tregnaghi A, Gamba PG, Midrio P. Early prenatal diagnosis of cloacal exstrophy with fetal magnetic resonance imaging. Fetal Diagn Ther 2008;24(04):437-439

52 Yamano T, Ando K, Ishikura R, Hirota S. Serial fetal magnetic resonance imaging of cloacal exstrophy. Jpn J Radiol 2011;29(09): 656-659

53 Clements MB, Chalmers DJ, Meyers ML, Vemulakonda VM. Prenatal diagnosis of cloacal exstrophy: a case report and review of the literature. Urology 2014;83(05):1162-1164

54 Allam ES, Shetty VS, Farmakis SG. Fetal and neonatal presentation of OEIS complex. J Pediatr Surg 2015;50(12):2155-2158

55 Kant SG, Bartelings MM, Kibbelaar RE, Van Haeringen A. Severe cardiac defect in a patient with the OEIS complex. Clin Dysmorphol 1997;6(04):371-374

56 Goto S, Suzumori N, Obayashi S, Mizutani E, Hayashi Y, SugiuraOgasawara M. Prenatal findings of omphalocele-exstrophy of the bladder-imperforate anus-spinal defects (OEIS) complex. Congenit Anom (Kyoto) 2012;52(03):179-181

57 Goyal A, Fishwick J, Hurrell R, Cervellione RM, Dickson AP. Antenatal diagnosis of bladder/cloacal exstrophy: challenges and possible solutions. J Pediatr Urol 2012;8(02):140-144

58 Chen C-P. Syndromes, disorders and maternal risk factors associated with neural tube defects (III). Taiwan J Obstet Gynecol 2008;47(02):131-140

59 Liang RI, Huang SE, Chang FM. Prenatal diagnosis of ectopia cordis at 10 weeks of gestation using two-dimensional and threedimensional ultrasonography. Ultrasound Obstet Gynecol 1997; 10(02):137-139

60 Kubba T, Khalil A, Abu-Rustum R, et al. Prenatal diagnosis of pentalogy of Cantrell at 11-13 weeks: evidence for a hexalogy. J Obstet Gynaecol 2013;33(01):85-86

61 Cakiroglu Y, Doger E, Yildirim Kopuk S, Babaoglu K, Caliskan E, Yucesoy G. Prenatal diagnosis of Cantrell's pentalogy associated with agenesis of left limb in a twin pregnancy. Case Rep Obstet Gynecol 2014;2014:314284

62 Gün I, Kurdoğlu M, Müngen E, Muhcu M, Babacan A, Atay V. Prenatal diagnosis of vertebral deformities associated with pentalogy of Cantrell: the role of three-dimensional sonography? J Clin Ultrasound 2010;38(08):446-449

63 Van Allen MI, Curry C, Walden CE, Gallagher L, Patten RM. Limbbody wall complex: II. Limb and spine defects. Am J Med Genet 1987;28(03):549-565

64 Chikkannaiah P, Dhumale H, Kangle R, Shekar R. Limb body wall complex: a rare anomaly. J Lab Physicians 2013;5(01):65-67 